OPEN ACCESS

Edited by:

Ashlie Martini,

University of California, Merced,

United States

Reviewed by:

Lelia Cosimbescu, Battelle, United States

Alpaslan Atmanli,

National Defense University, Turkey

*Correspondence:

Gary L. Doll

gdol/@uakron.edu

Specialty section:

This article was submitted to Engine and Automotive Engineering,

a section of the journal

Frontiers in Mechanical Engineering

Received: 09 January 2019

Accepted: 28 March 2019

Published: 01 May 2019

Citation:

LotfizadehDehkordi B, Shiller PJ and Doll GL (2019) Pressure- and Temperature-Dependent Viscosity

Measurements of Lubricants With

Polymeric Viscosity Modifiers.

Front. Mech. Eng. 5:18.

doi: 10.3389/fmech.2019.00018
Pressure- and

\section{Temperature-Dependent Viscosity Measurements of Lubricants With Polymeric Viscosity Modifiers}

\author{
Babak LotfizadehDehkordi, Paul J. Shiller and Gary L. Doll* \\ Timken Engineered Surfaces Laboratories, The University of Akron, Akron, OH, United States
}

The pressure-viscosity coefficient, $\alpha$, is a measure of the pressure dependence of the viscosity of the liquid in elastohydrodynamic lubrication (EHL). There seems to be confusion around the understanding of the pressure-viscosity response in the inlet zone. In this paper the values of $\alpha$ were obtained from measurements of viscosity as a function of pressure and offers a understanding on the piezoviscous effect at various inlet pressures for those liquids. Moreover, the viscosities of several commercial engine oils and laboratory blends of mineral and synthetic base oils with polymer additives were measured at pressures up to $1 \mathrm{GPa}$ and at temperatures of $40^{\circ}, 75^{\circ}$, and $100^{\circ} \mathrm{C}$. It was observed in some of these materials The significant changes within viscosity are temperature- and pressure-dependent. Analysis of the experimental results indicated that the solidification (significant increase viscosity) is due to liquid-solid phase transitions occurring in the lubricant's polymer additives. Thus, this paper gives evidence on the role of molecular weight and concentration of polymer and its influence on the pressure and temperature-dependent onset of the phase transitions. This transition has not been discussed in the open literature and is not accounted for in current bearing design using the Barus equation or the modified Yasatomi equation and may be the cause of some bearing damage modes.

Keywords: elastohydrodynamic (EHL), lubricant, polymer additives, extreme pressure, viscosity modifiers (VM), viscosity

\section{INTRODUCTION}

Service lives of bearings and gears are dependent upon the use of lubricants. Lubricants reduce friction and wear in highly loaded contacts, and provide cooling, corrosion resistance, and other benefits. Forces in mechanical components are transmitted through a thin lubricant layer that must be viscous enough to form and sustain a fluid film between the contacting surfaces.

Viscosity is such an important property in the design of lubricants that it is desirable to minimize the variations in its structure created by high temperatures. Commercial lubricants such as multiviscosity automotive engine oils accomplish this with polymer additives used as viscosity modifiers (VM) or viscosity index improvers (VII). These soluble polymers help to reduce the thermal changes in viscosity while maintaining desirable lubricant performance such as film formation and pumping ability. 
Knowledge of the properties of the lubricant flowing through a contact is essential to maintaining desirable lubricant performance and component life. Fluid flow in which the shear stress is not linearly proportional to the shear rate (i.e., non-Newtonian behavior) is common in lubricants containing polymer additives. Various hypotheses have been suggested and tested during the last few decades to describe the non-Newtonian nature of lubricants. A simple power law response is the most popular model, and one that has been successfully used to describe both pseudoplastic and dilatant fluids (non-Newtonian fluid where the shear viscosity increases with applied shear stress) (Dyson and Wilson, 1965; Bayraktar and Kiran, 2000; Chu et al., 2006).

$$
\eta=\left(\frac{\tau}{\dot{\gamma}}\right)^{n}
$$

where $\eta$ is the viscosity, $\tau$ is the shear stress, and $\dot{\gamma}$ is the shear rate. The power law exponent " $n$ " is the rheological index. Fluids with $n>1, n=1$, and $n<1$ correspond to a dilatant fluid, a Newtonian fluid, and a pseudoplastic fluid, respectively.

Highly loaded machine elements tend to operate in elastohydrodynamic lubrication (EHL) regimes where the loads are high enough to elastically deform their surfaces and generate extremely high pressures in the contact. In EHL theory, lubricant films are usually assumed to behave in a Newtonian manner. However, the lubricant in an EHL contact experiences rapid and extremely large pressure variations on the order of 1 to $3 \mathrm{GPa}$ (Khonsari and Booser, 2008), rapid transit times on the order of $4 \mathrm{~ms}$, and-particularly with sliding contactshigh shear rates that could be on the order of $10^{6} \mathrm{~s}^{-1}$. These conditions have called into question the normal assumptions of Newtonian behavior of fluid films in EHL conjunctions (Hamrock et al., 2004).

Early explorations of high-pressure effects on the viscosity of lubricants were performed by Bridgman using a falling body high-pressure viscometer (Bridgman, 1949). Bridgman reported that the viscosity of oils increased with increasing pressure. His results provided the pressure-viscosity coefficient data that became utilized in EHL theory (Bair, 2000).

In 1949, Grubin developed the EHL principles involved in the lubrication of rolling contacts to predict film thickness (Grubin and Vinogradova, 1949). In the late 1970s, Hamrock and Dowson developed advanced numerical approaches to calculate the isothermal EHL of elliptical contacts (Dowson and Hamrock, 1976; Hamrock and Dowson, 1976, 1978). Four non-dimensional parameters were defined: speed $(U)$, material $(G)$, load $(W)$, and dimensionless film thickness $(H)$. The general formula for calculating the film thickness of a lubricant in a contact area can be expressed as:

$$
H=K U^{a} G^{b} W^{c}
$$

where $K, a, b$, and $c$ are numbers that vary with the contact geometry. The $U$ and $W$ parameters are easily derived from the test and application conditions, but the material parameter, $G$ $=\alpha^{*} E$, depends upon $\alpha^{*}$-which is a measure of the strength of the piezoviscous response known as the pressure-viscosity coefficient. $\alpha^{*}$ is a property of the lubricant and cannot be selected like speed or load. $E^{\prime}$ is the effective modulus of elasticity.

After many years of research, there is still no well-accepted definition for the pressure-viscosity coefficient (Vergne and Bair, 2014). The most direct approach to obtaining the pressureviscosity coefficient of a lubricant is by measuring its highpressure viscosity. However, most of the reported pressure viscosity data are derived indirectly from a measurement of the central EHL film thickness (e.g., ball-on-glass plate configuration) (Bair, 2000). In the direct approach, $\alpha^{*}$ was originally estimated from an exponential dependence of viscosity on pressure; i.e., the Barus equation:

$$
\eta=\eta_{0} e^{\alpha p}
$$

The $\alpha$ values in the Barus equation do not correlate with measured film thickness values at relatively low pressures. An improved pressure viscosity coefficient can be used that is based on the asymptotic isoviscous pressure coefficient (Blok, 1963; Bair, 2015). In the direct approach using high-pressure viscosity data, the asymptotic local pressure viscosity coefficient is defined by Bair (Bair, 2007):

$$
\alpha^{*} \approx\left[\frac{\eta_{0}}{\alpha_{N} \eta_{N}}+\sum_{i=1}^{N} \frac{\eta_{0}}{\alpha_{i}} \frac{\eta_{i}-\eta_{i-1}}{\eta_{i} \eta_{i-1}}\right]^{-1}
$$

where $\alpha_{i}$ is the local piezoviscous factor,

$$
\alpha_{i}=\frac{\ln \left(\frac{\eta_{i}}{\eta_{i-1}}\right)}{\left(p_{i}-p_{i-1}\right)}
$$

and $\eta_{i}=\eta\left(p_{i}\right)$ is determined from high-pressure viscosity measurements ( $i$ refers to each measurement and $N$ is the number of experiments). Asymptotic isoviscous pressure coefficients require measurements of viscosity as a function of pressure as well as the local pressure viscosity coefficient. Hence, the knowledge of viscosity as a function of pressure and temperature is desirable in order to obtain a realistic pressure viscosity coefficient and estimate of the EHL film thickness.

Prior investigations have been reported on the high-pressure rheology of lubricants (Bair and Winer, 1979; Bair et al., 2001; Chapkov et al., 2007; Bair, 2013; Vergne and Bair, 2014). In these studies, a linear variable differential transformer was used in a falling body viscometer to track the sinker position in a viscometer chamber (Bair and Winer, 1980). Bair and Qureshi studied the pressure-viscosity behavior of motor oil base stocks and polyalphaolefin oil (PAO-4) up to 1.4 $\mathrm{GPa}$, establishing confidence in the high-pressure falling body viscometer (Bair and Qureshi, 2002) as a measurement tool. A phase separation in motor oil base stock was observed at about $1 \mathrm{GPa}$ at $70^{\circ} \mathrm{C}$ in refined mineral oils. It was suggested that this was due to the separation of a waxy component of the mineral oil that is not seen in PAO oil. Bair and Qureshi also noted a linear pressure-viscosity relationship in API Group III and PAO-4 samples tested up to $100 \mathrm{MPa}$ at 
$180^{\circ} \mathrm{C}$. The authors postulated that this behavior may have been due to the magnitude and direction of the change in bulk modulus and free volume with pressure and the interaction between them.

Akki, Bair, and Abhiraman used a falling body highpressure viscometer to measure the viscosities of polyethylenedecalin solutions up to $600 \mathrm{MPa}$ and at temperatures above $100^{\circ} \mathrm{C}$ (Akki et al., 1995). In that study, it was speculated that a significant increase in viscosity with pressure might be explained by crystallization of the sample that may have partial solidification. Pressure-induced crystallization was observed by light scattering, but at higher pressures than those obtained with the high-pressure viscometer. This difference in pressure was attributed to shear-induced nucleation in the sample.

Bair and Winer also examined the high-pressure viscosity of motor oils with different SAE grades at $40^{\circ}, 100^{\circ}$, and $150^{\circ} \mathrm{C}$ at pressures up to $550 \mathrm{MPa}$ (Bair and Winer, 1988). Low shear viscosity results showed almost the same pressureviscosity trend between standard formulations and fuel economy formulations. However, two samples showed an increase in viscosity at just under $300 \mathrm{MPa}$ and $40^{\circ} \mathrm{C}$. This effect had been seen before and it was observed there was a separation of the solid phase from the oil. Contrary to previous studies, Mary et al. did not observe any anomalous increases in viscosity with polymer-thickened lubricants under high pressure (Mary et al., 2013).

There is a lack of consensus in the literature concerning the viscosity of polymer-blended lubricants at high pressure. Therefore, experimental studies of the highpressure behavior of lubricants with polymer additives are important for developing a better understanding of the rheological properties of these materials. This research presents the results of high-pressure viscosity experiments performed on several commercial engine oils and laboratoryformulated blends of synthetic oil with polyisobutylene polymer additives.

\section{MATERIALS AND METHODS}

Two sets of experiments are reported in this study. In the first set, the pressure- and temperature-dependent viscosities of six fully formulated commercial multigrade engine oils with polymer VM additives were measured. These six oils consisted of three conventional mineral oils and three synthetic polyalphaolefin (PAO) oils. Each set of three was from the same manufacturer. Table 1 lists the oils and some of their properties that were supplied by the manufacturers. Detailed information on the compositions of these lubricants is not available since these samples were commercial off-the-shelf products.

A second set of experiments was performed to determine the effects of polymer molecular weight and concentration on the pressure and temperature dependence of the viscosity. Four samples were blended that consisted of two polyisobutylene (PIB) molecular weights at two different concentrations. Polyisobutylene was chosen as the additive in these experiments
TABLE 1 | Properties of commercial engine oils utilized in this study.

\begin{tabular}{|c|c|c|c|}
\hline \multicolumn{2}{|c|}{ Mineral oils (M) } & \multicolumn{2}{|c|}{ Synthetic oils (S) } \\
\hline SAE grade & $\begin{array}{c}\text { Density } \\
\mathrm{gr} / \mathrm{ml}\left(22^{\circ} \mathrm{C}\right)\end{array}$ & SAE Grade & $\begin{array}{c}\text { Density } \mathrm{gr} / \mathrm{ml} \\
\left(15.6^{\circ} \mathrm{C}\right)\end{array}$ \\
\hline $5 \mathrm{~W}-30(\mathrm{M})$ & 0.961 & $5 \mathrm{~W}-30$ (S) & 0.856 \\
\hline 10W-30 (M) & 0.927 & 10W-30 (S) & 0.861 \\
\hline $20 \mathrm{~W}-50$ (M) & 0.924 & OW-40 (S) & 0.85 \\
\hline
\end{tabular}

because it is a common viscosity modifier used in lubricants (Bruce, 2012). The first group of samples in this set consisted of a low molecular weight PIB (about 75,000 g/mole), and is labeled "PIB A." The second group consisted of mixtures of a higher molecular weight PIB (about $340,000 \mathrm{~g} / \mathrm{mol}$ ) and is labeled "PIB B." Molecular weights and other properties of the PIB samples provided by the manufacturers are listed in Table 2. PIB was blended into an ISO VG 10 PAO base oil at 5\% and $10 \%$ for the "PIB A" samples, and at 10 and $15 \%$ for the "PIB B" samples.

High-pressure viscosity measurements were carried out in two falling body viscometers: a "high pressure" viscometer capable of obtaining pressures up to $400 \mathrm{MPa}$ and an "ultra-high pressure" viscometer capable of obtaining pressures over $1 \mathrm{GPa}$. A thorough description of the falling body viscometers can be found in the literature (Bair and Winer, 1980). Measurements performed in these viscometers are based upon Stokes flow, in which the viscosity is proportional to the velocity of the falling body due to gravity when the body reaches terminal velocity. The temperature was regulated by flowing air past heaters and around the viscometer chamber. Viscosities were measured at $40^{\circ}, 75^{\circ}$, and $100^{\circ} \mathrm{C}$ and over 10 separate pressure values. For each measurement, the viscometer was allowed to come to equilibrium for at least $30 \mathrm{~min}$ in order to ensure the stability of the pressure and temperature. The viscosity experiments were performed with both solid sinker (cylinder with no central flow path and will reach at a velocity of $1 \mathrm{~mm} / \mathrm{s}$ for a viscosity of about 0.03 Pa.s and applies a shear stress of about $6 \mathrm{~Pa}$ ) and hollow body sinkers (is a tube with a central hole that falls with velocity of $1 \mathrm{~mm} / \mathrm{s}$ at a viscosity of 5.5 Pa.s. and applies shear stress to the sample inside chamber $\sim 1 \mathrm{~Pa}$ and $30 \mathrm{~Pa}$ between the cup and hollow sinkers). The uncertainty of the values are difficult to determine due to the complexity and diversity of the samples but the RMS deviation of the $5 \mathrm{~W}-30$ oil sample about the Yasutomi regression line is $94 \mathrm{mPa} . \mathrm{s}$.

Tribological experiments were performed on a Wedeven Associates WAM6 Machine ball-on-disk tribometer with AISI 52100 balls and disks. PAO10 and the commercial $5 \mathrm{~W}-30$ oils were used as the lubricants. The WAM6 was operated with a 5\% slide-to-roll ratio, durations of $180 \mathrm{~s}$, and at temperatures of $40^{\circ}$, $75^{\circ}$, and $100^{\circ} \mathrm{C}$. In each test, applied loads were ramped from 50 to $160 \mathrm{~N}$, producing average contact stresses of 700 to 1,000 $\mathrm{MPa}$ and maximum contact stresses of 1,000 to 1,550 MPa. After each test, wear scars produced on the disks were examined using a Zygo NewView ${ }^{\mathrm{TM}}$ 7,300 optical interferometer. 
TABLE 2 | Properties of PIB samples used in this study.

\begin{tabular}{|c|c|c|c|c|c|}
\hline Sample & Density at $20^{\circ} \mathrm{C}(\mathrm{gr} / \mathrm{cc})$ & Crystallization $\left({ }^{\circ} \mathrm{C}\right)$ & $\mathrm{T}_{\mathrm{g}}\left({ }^{\circ} \mathrm{C}\right)$ & Molecular weight (Da) & $M_{w} / M_{n}$ \\
\hline PIB A & 0.92 & 90 & -64 & 75,000 & 3.4 \\
\hline PIB B & 0.92 & 90 & -64 & 340,000 & 5 \\
\hline
\end{tabular}

\section{RESULTS}

\section{Viscosity Measurements of Commercial Engine Oils With a Solid Sinker}

Figure 1 displays the pressure- and temperature-dependent viscosities of the commercial engine oils as measured with the solid body sinker. Comparisons are shown for lubricants with mineral (M) and synthetic (S) base stocks in Figures 1A,B (10W-30 oils) and Figures 1C,D (5W-30 oils). In all samples and at all temperatures, the viscosity increased approximately exponentially (linearly with a log scale) with pressure having a concave down shape up to about $500 \mathrm{MPa}$. This is the expected behavior of viscosity according to Equations 1-4. However, at pressures above $500 \mathrm{MPa}$, most of the samples showed a marked departure from this expected behavior, eventually obtaining viscosities so large that all movement of the sinker ceased. Solid triangle symbols in the figures denote lower bound estimates of the viscosity at the pressure where all motion of the solid sinker ceased. Viscosities of samples that displayed a stoppage of sinker motion returned to their initial values after reducing the pressure. That is, the uncharacteristic viscosity increases occurring in these lubricants were reversible.

Anomalous increases in viscosity at specific temperatures were observed at similar pressures for the $5 \mathrm{~W}-30$ and $10 \mathrm{~W}-30$ lubricants for both synthetic (S) and mineral (M) base oils, suggesting that the departures from expected behavior were not attributable to the base oil. No sinker stoppage was observed for the $0 \mathrm{~W}-40$ sample at the three temperatures studied. When sinker stoppage occurred in these experiments, it was observed to occur when the viscosity exceeded about $10^{5} \mathrm{mPa}$-s. Although the viscosity of the $0 \mathrm{~W}$ 40 oil increased less with pressure than the $5 \mathrm{~W}-30,10 \mathrm{~W}$ 30 , or $20 \mathrm{~W}-50$ oils, it is possible that the $0 \mathrm{~W}-40$ may experience sinker stoppage at pressures $>1 \mathrm{GPa}$. In fact, there appears to be an upward inflection in the $40^{\circ} \mathrm{C}$ data corresponding to the measurements performed at 800 and 1,000 MPa. However, there are not enough data points above the $10^{5} \mathrm{mPa}$-s level to determine if sinker stoppage was imminent.

Pressure increments of $100 \mathrm{MPa}$ were normally used in these experiments. That is, after measuring the viscosity at one pressure value, the next data point was obtained at $p+100$ $\mathrm{MPa}$. However, the viscosities of the 5W-30 (S) and 10W-30 (S) samples were also measured with 20 and $50 \mathrm{MPa}$ pressure increments at $40^{\circ} \mathrm{C}$ in Figures 1B,D, respectively, and the data are indicated by the green circles. The results show that increasing the pressure in smaller increments can delay the onset of sinker stoppage.

\section{Viscosity Measurements of Laboratory- Formulated PAO/PIB Mixtures With a Solid Sinker}

Figure 2 displays the viscosity of neat PAO ISO VG 10 without polymer additives. At all temperatures, the viscosity increased approximately exponentially with pressure, which again is the expected behavior according to Equations 14. Figures 3A-D show viscosity as a function of pressure and temperature for the two PIB mixtures. While the viscosity of PAO with the low-molecular-weight polymer ("PIB A") did not depart from expected behavior at the $10 \mathrm{wt} \%$ concentration at any of the three temperatures, sinker stoppage was observed around $1 \mathrm{GPa}$ and $40^{\circ} \mathrm{C}$ in the PAO with 15 wt $\%$ PIB A. Comparison of the viscosity curves obtained for PAO blended with the higher-molecularweight PIB B shows that sinker stoppage occurred at high pressures in the $40^{\circ}$ and $75^{\circ} \mathrm{C}$ tests performed on the sample with $10 \mathrm{wt} \%$ PIB B, but not in the sample with $5 \mathrm{wt} \%$ PIB B. Collectively, these data indicate that sinker stoppage depended upon both the molecular weight and concentration of the polymer.

\section{Tribological Measurements of PAO 10 and $5 \mathrm{~W}-30$ Oils}

Figures 4, 5 display the analytical results of wear tracks formed on disks tested in the PAO 10 and 5W-30 oils, respectively. Each figure contains a false color surface map, an optical image, a line scan, and surface metrics (PV and Ra) obtained from the wear scars by 3D optical interferometry. Figure 4 illustrates that the wear generated on the disks in the PAO 10 oil testing was dependent on the temperature as with rise in the temperature led to decrease in the lubricant film thickness, thus as expected a greater amount of wear was observed on the disk tested at $100^{\circ} \mathrm{C}$ than on the disk tested at $40^{\circ} \mathrm{C}$.

The consequences of the anomalous viscosity behavior of the $5 \mathrm{~W}-30$ oil at $40^{\circ} \mathrm{C}$ can be seen in Figure 5. Specifically, significantly more wear was observed in the $40^{\circ} \mathrm{C}$ test than in the $75^{\circ}$ and $100^{\circ} \mathrm{C}$ measurements that were attributed to the loss of lubricant at the contact, i.e., solidification. The line trace in the $40^{\circ} \mathrm{C}$ data in Figure 5 reveals a wear groove in the disk that is about $1.5 \mu \mathrm{m}$ deep. No other wear grooves are evident in the line traces for any of the temperature measurements in Figure 4 or in the $75^{\circ}$ and $100^{\circ} \mathrm{C}$ temperature measurements in Figure 5. The tribological behavior of the 5W30 oil at $40^{\circ} \mathrm{C}$ correlates with its anomalous viscosity behavior (see Figure 1D), and provides compelling evidence that the two effects are related. 

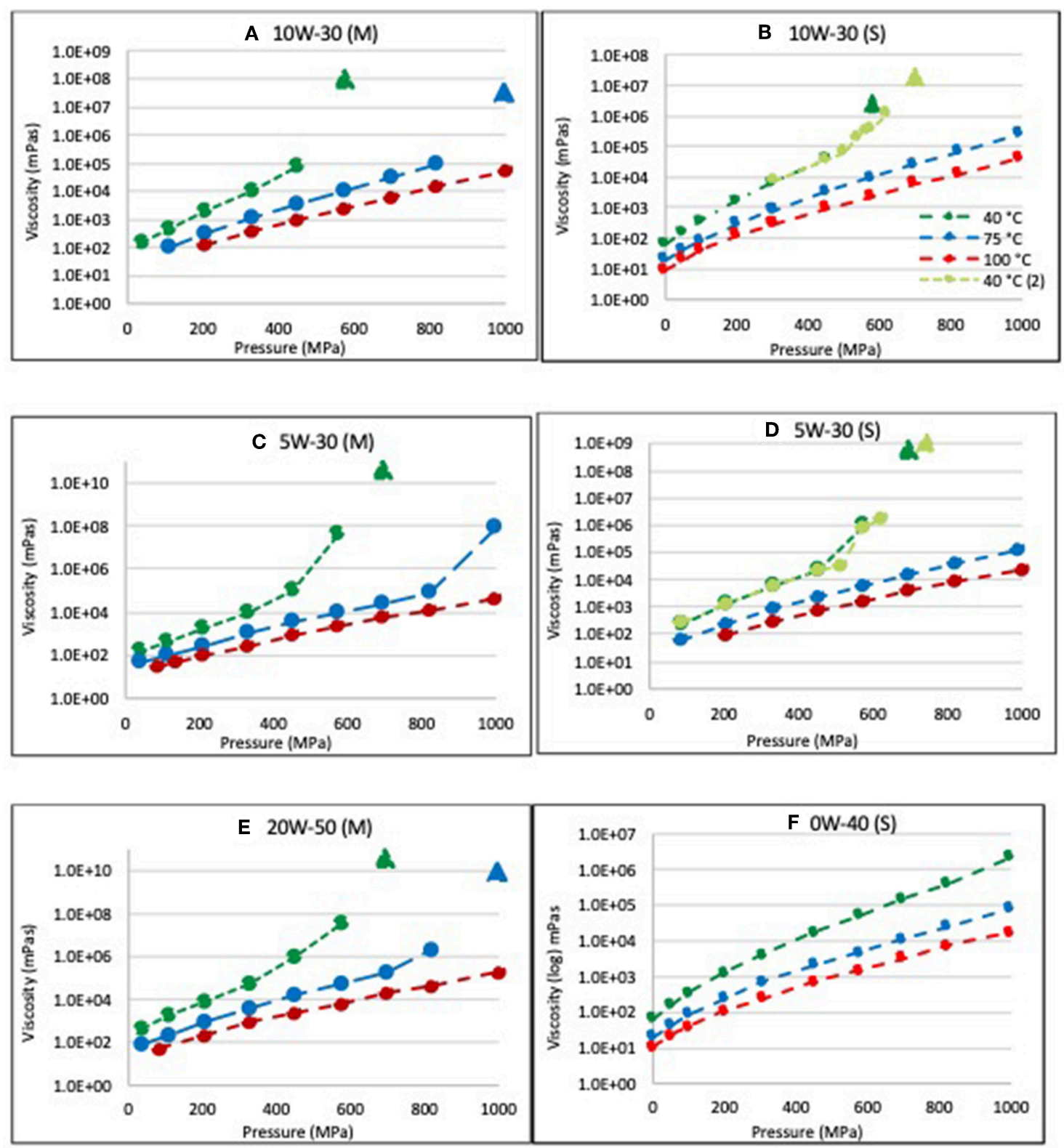

FIGURE 1 | Pressure-temperature-viscosity measurements of mineral oil-based (M) and synthetic oil-based (S) commercial engine oils. (A) 10W-30 (M), (B) 10W-30 (S), (C) 5W-30 (M), (D) 5W-30 (S), (E) 20W-50 (M), and (F) 0W-40 (S). Kinetic effects on the viscosity can be observed in Figures (B,D) in the $40^{\circ} \mathrm{C}$ data where the standard procedure of instantaneous pressure application is compared to applying the pressure in increments of 20-30 MPa.

\section{DISCUSSION}

Results reported in the previous section show that the viscosities of both commercial lubricants and laboratory formulated PAO with polymer additives exhibited significant departures from their expected behavior at high pressure. These departures took the form either of an inflection when the viscosity exceeded about $10^{5} \mathrm{mPa}$-s, and/or an abrupt solid sinker stoppage where the viscosity became infinite. Both of these observations are in conflict with the assumptions made in classical EHL film thickness formulae that have a smooth, monotonic dependence of viscosity with pressure. This contradictory behavior could lead to an inaccurate prediction of film thickness in a tribological contact. Knowledge of the viscosity in the inlet zone (low pressure) of a contact is required to calculate the minimum film thickness of a lubricant. The anomalous increases in viscosity observed in this study occur at pressures well-below typical contact pressures experienced by many mechanical components. Anomalous behavior in lubricant viscosity that takes place in the inlet zone of a contact may significantly impact the formation 
of an elastohydrodynamic film, and appears to have done so in the WAM6 experiments performed on the commercial 5W-30 engine oil at $40^{\circ} \mathrm{C}$.

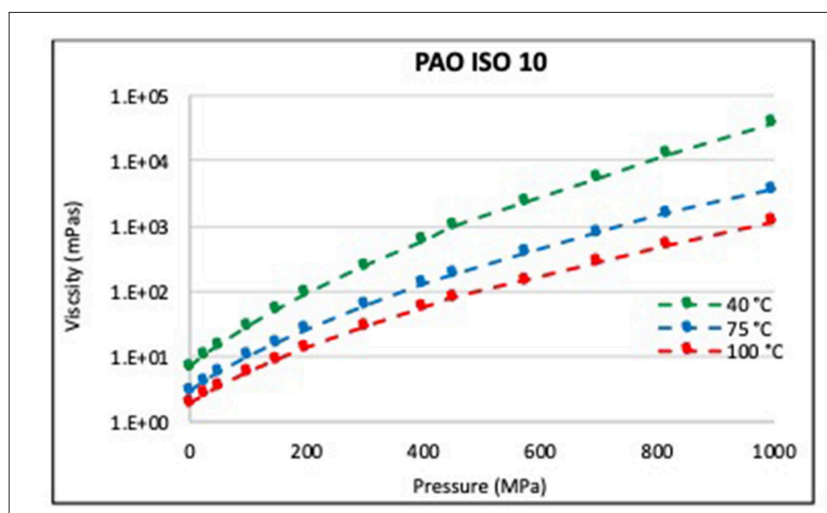

FIGURE 2 | Viscosity ( $\mathrm{mPa}-\mathrm{s}$ ) as a function of pressure and temperature for PAO ISO 10.
Anomalous increases in viscosity were observed at similar pressures for synthetic- and mineral-based $5 \mathrm{~W}-30$ and $10 \mathrm{~W}$ 30 commercial engine oils, which indicates that the behavior was independent of the base oil type. Furthermore, since the anomalous viscosity behavior was observed in the PAO/PIB mixtures, but not in neat PAO, it must be concluded that the anomalous behavior arose from the polymer additives. Results of the PAO/PIB measurements also show that the concentration of the PIB influenced the viscosity pressure response. Viscosity measurements of the PAO/PIB mixtures with different molecular weights indicate that anomalous viscosity behavior was more likely to occur in polymers with larger molecular weights.

The observation that the viscosity of the commercial oils and laboratory blends can become infinite with pressure indicates that the polymer additives or the solutions can transform into solid or semi-solid materials at high pressures. Liquid-solid phase transitions of polymers are categorized as either glass transitions or crystallization. Since it is generally assumed that viscosity will exceed $10^{-12} \mathrm{mPa}$-s from a glass transition (Barlow et al., 1969; Harrison, 1976; Alsaad et al., 1978), if a phase transition is occurring in the PIB then it is probably crystallization
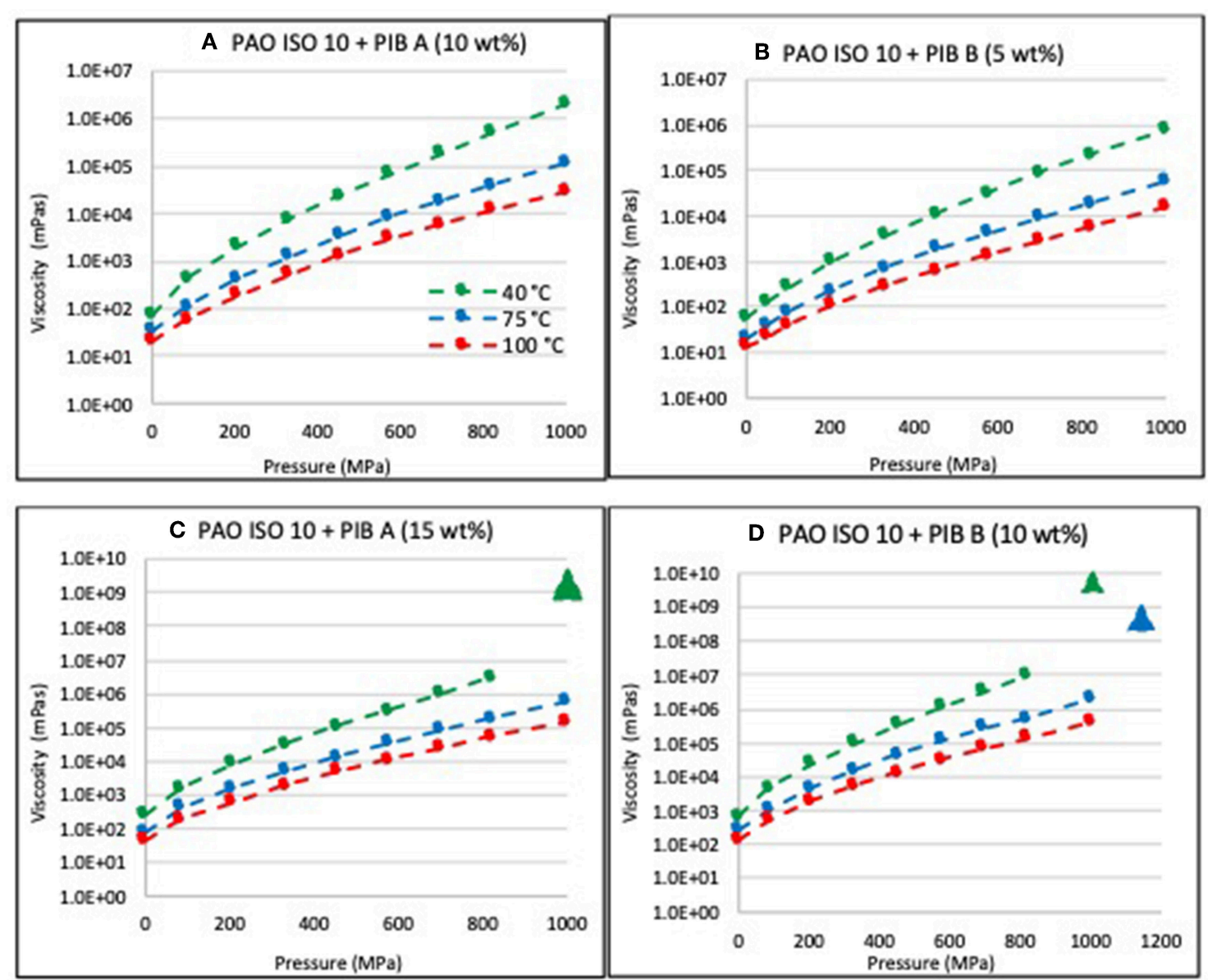

FIGURE 3 | Viscosity (mPa-s) as a function of pressure and temperature for (A) mixture of PAO ISO 10 and PIB A (10 wt\%), (B) mixture of PAO ISO 10 and PIB B (5 wt\%), (C) mixture of PAO ISO 10 and PIB A (15 wt\%), and (D) mixture of PAO ISO 10 and PIB B (10 wt\%). The triangle symbols indicate the lowest estimate of viscosity corresponding to the pressure where movement of the sinker ceased. 


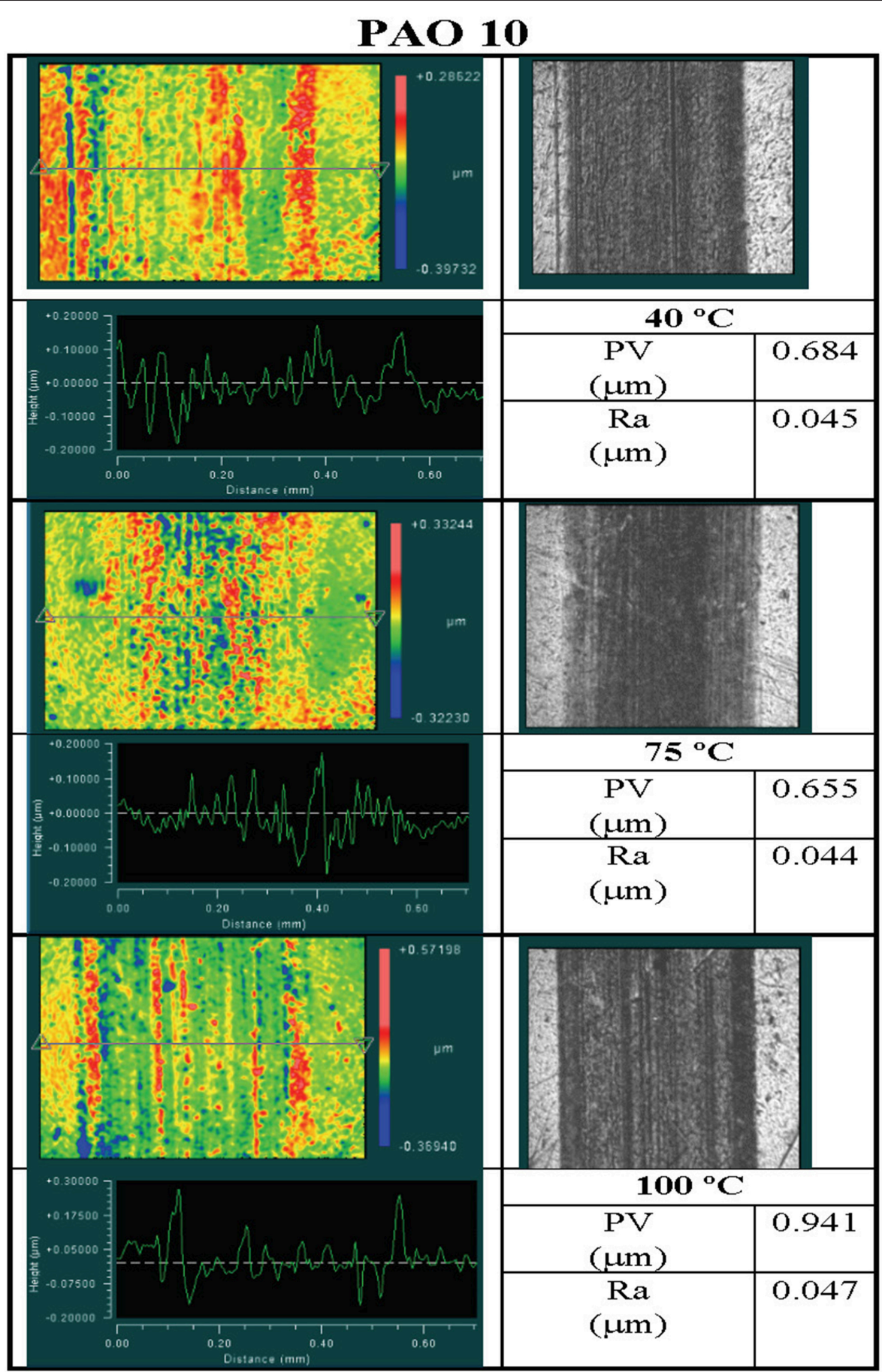

FIGURE 4 | Analysis of wear tracks formed on disks at $40^{\circ}, 75^{\circ}$, and $100^{\circ} \mathrm{C}$ in tests performed with the PAO 10 oil. Clockwise in each temperature box are a false color surface map, an optical image of the wear track, the values of PV and Ra in the wear track, and a line trace across the wear track.

(LotfizadehDehkordi et al., 2016). A phase separation (i.e., solidified polymers have come out of solution with the oil) occurring at critical temperature and pressure combinations could cause the falling of a solid sinker to cease if the solid particles were too large to pass between the sinker and the chamber wall. On the other hand, segregated solid particles in the oil should easily pass through the bore of a hollow sinker, and the descent rate of the hollow sinker may be slowed, but not stopped.

Since viscosity measurements performed on the 5W-30 oil also resulted in stoppage of the hollow sinkers, it may be assumed that either the entire solution solidified or the solidified polymers were not segregated from each other and may have 


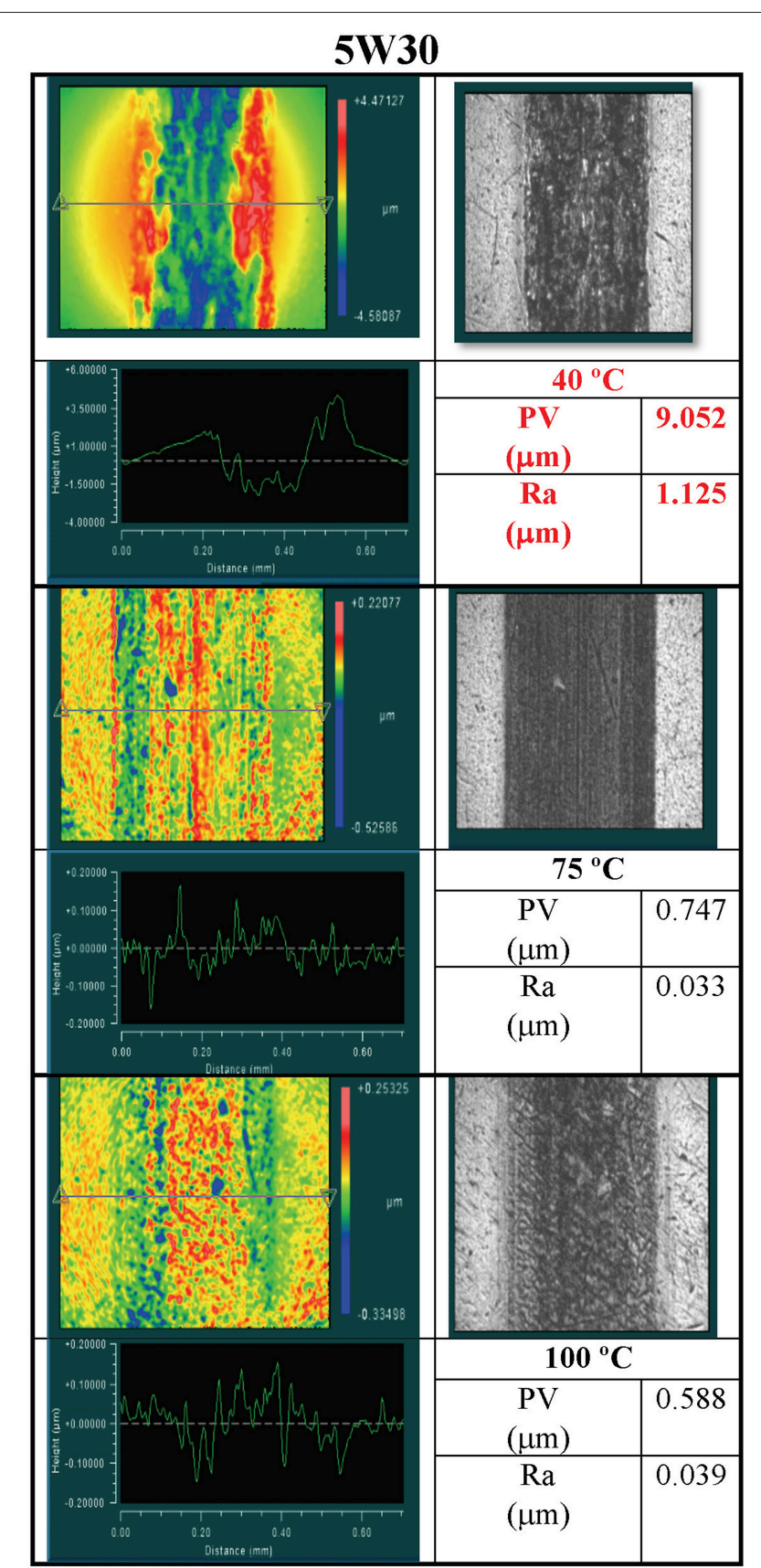

FIGURE 5 | Analysis of wear tracks formed on disks at $40^{\circ}, 75^{\circ}$, and $100^{\circ} \mathrm{C}$ in tests performed with the $5 \mathrm{~W}$-30 oil. Clockwise in each temperature box are a false color surface map, an optical image of the wear track, the values of PV and $\mathrm{Ra}$ in the wear track, and a line trace across the wear track.

formed solid mono-domains. Interpretations of the tribological test results favor the viewpoint that the solidified polymers were no longer in solution with the base oil at critical temperatures and contact pressures. That is, at temperatures and contact pressures consistent with sinker stoppage in the viscosity experiments, the wear scar generated from the tribological testing is consistent with the appearance of scars formed from an extremely thin lubricant film with abrasive particles passing through the contact. Tribologically, polymers that solidify in the inlet zone of a contact could function as debris particles and create abrasive surface wear if the lubricant film is thin enough. If the solidified polymers fall out of solution with the oil, then the oil thickness is expected to decrease as a result of the absence of the viscosity-modifying function supplied by the liquid-state polymer. It is therefore believed that the combination of a thinner lubricant film with solid particles flowing through the contact was responsible for the large amount of wear created in the tribological testing with the $5 \mathrm{~W}-30$ oil at $40^{\circ} \mathrm{C}$.

Examinations of viscosity measurements performed on the commercial engine oils indicate that increasing the pressure in smaller increments moved the onset of the solid sinker stoppage to larger pressures. Increasing the pressure in larger increments (e.g., $100 \mathrm{MPa}$ ) may have allowed insufficient time for the molecules to organize, so the phase transitions occurred at lower pressures. On the other hand, applying pressure in smaller increments may have given the polymer molecules sufficient time to organize, so the phase transitions occurred at higher pressures. Since crystallization has slower kinetics than glass transitions in polymers, the data support a crystallization mechanism more favorably than a glass transition mechanism.

Based upon the results presented in this study, phase transitions and separations of polymeric viscosity-modifying agents from the oils significantly altered the estimated lubricant film thickness at critical temperatures and pressures. Clearly, the utilization of a pressure viscosity coefficient in classical minimum film thickness calculations becomes questionable for lubricants at pressures greater than those required for the onset of the polymer phase transitions. Finally, the future studies will involve to study in other polymers types like PAMAs (Polyalkyl methacrylate) and OCPs (Olefin Copolymer) as well as characterizing the polymers using DSC (Differential Scanning Calorimetry).

\section{CONCLUSIONS}

Experiments performed in this study indicated that polymer additives in oils can undergo phase transitions at pressures $<1 \mathrm{GPa}$. Viscosities of the fully formulated commercial and laboratory-formulated oils took the form of positive inflections (a change of slope) in the pressure-viscosity curve or abrupt transformations of the oil to a low-viscosity fluid containing solid or semi-solid materials at critical temperatures and pressures. Positive inflections in the pressure-dependent viscosity occurred when the viscosity exceeded about $10^{5} \mathrm{mPa}$-s.

Pressure- and temperature-dependent phase changes observed rheologically in the lubricants were also found to coincide tribologically with accelerated wear resulting from a collapse of the lubricant film thickness and the introduction of abrasive solids in the contact. In viscosity experiments performed on PAO/PIB blends, phase transitions were observed to occur and found to correlate with the molecular weights and concentrations of the PIB polymer additives. Increasing the pressure in smaller increments was found to increase the pressure associated with the phase transitions, which suggests 
that there may be a kinetic effect associated with the polymer phase transition.

\section{AUTHOR CONTRIBUTIONS}

BL performed the experiments and conducted primary analysis. PS provided guidance on lubrication. GD provided guidance on tribology and wrote manuscript.

\section{FUNDING}

This research was funded by the Timken Company of Canton, Ohio.

\section{REFERENCES}

Akki, R., Bair, S., and Abhiraman, A. (1995). Low shear viscosity and crystallization in dilute solutions of polymers at high pressures: falling body viscometry of high molecular weight polyethylene solutions. Polymer Eng. Sci. 35, 1781-1784. doi: $10.1002 /$ pen.760352207

Alsaad, M., Bair, S., Sanborn, D., and Winer, W. (1978). Glass transitions in lubricants: its relation to elastohydrodynamic lubrication (EHD). J. Tribol. 100, 404-416. doi: 10.1115/1.3453197

Bair, S. (2000). Pressure-viscosity behavior of lubricants to $1.4 \mathrm{GPa}$ and its relation to EHD traction. Tribol. Transac. 43, 91-99. doi: 10.1080/10402000008982317

Bair, S. (2007). High Pressure Rheology for Quantitative Elastohydrodynamics. Amsterdam: Elsevier.

Bair, S. (2013). "High pressure viscometers," in Encyclopedia of Tribology eds Q. J. Wang and Y. W. Chung (Boston, MA: Springer), 1663-1670. doi: 10.1007/978-0-387-92897-5_600

Bair, S. (2015). A critical evaluation of film thickness-derived pressure-viscosity coefficients. Lubricat Sci. 27, 337-346. doi: 10.1002/ls.1284

Bair, S., Jarzynski, J., and Winer, W. O. (2001). The temperature, pressure and time dependence of lubricant viscosity. Tribol. Int. 34, 461-468. doi: 10.1016/S0301-679X(01)00042-1

Bair, S., and Qureshi, F. (2002). Accurate measurements of pressureviscosity behavior in lubricants. Tribol. Transac. 45, 390-396. doi: 10.1080/10402000208982564

Bair, S., and Winer, W. (1979). Shear strength measurements of lubricants at high pressure. J. Tribol. 101, 251-257. doi: 10.1115/1.3453339

Bair, S., and Winer, W. (1980). Some observations on the relationship between lubricant mechanical and dielectric transitions under pressure. J. Tribol. 102, 229-234. doi: 10.1115/1.3251481

Bair, S., and Winer, W. O. (1988). Shear rheological characterization of motor oils. Tribol. Transact. 31, 317-324. doi: 10.1080/10402008808981829

Barlow, A., Erginsav, A., and Lamb, J. (1969). Viscoelastic relaxation in liquid mixtures. Proc. R. Soc. Lond. 309, 473-496. doi: 10.1098/rspa.1969.0053

Bayraktar, Z., and Kiran, E. (2000). Miscibility, phase separation, and volumetric properties in solutions of poly(dimethylsiloxane) in supercritical carbon dioxide. J Appl Polymer Sci. 75, 1397-1403. doi: 10.1002/(SICI)10974628(20000314)75:11<1397::AID-APP12>3.0.CO;2-F

Blok, H. (1963). "Inverse problems in hydrodynamic lubrication and design directives for lubricated flexible surfaces." In Proceedings of the International Symposium on Lubrication and Wear, eds D. Muster, B. Sternlicht, (Houston, TX; Berkeley, CA: McCutchan Publishing), 7-79.

Bridgman, P. W. (1949). Viscosities to $30,000 \mathrm{Kg} / \mathrm{Cm}^{3}$. Proc. Am. Acad. Arts Sci. 77, $117-128$

Bruce, R. W. (ed.) (2012). Handbook of Lubrication and Tribology: Theory and Design, Vol. 2. London: CRC Press, Taylor and FrancesGroup.

Chapkov, A., Bair, S., Cann, P., and Lubrecht, A. (2007). Film thickness in point contacts under generalized Newtonian EHL conditions: numerical and experimental analysis. Tribol Int. 40, 1474-1478. doi: 10.1016/j.triboint.2007.01.002

Chu, H. M., Li, W. L., and Chang, Y. P. (2006). Thin film elastohydrodynamic lubrication-a power-law fluid model.

\section{ACKNOWLEDGMENTS}

The authors are grateful to The Timken Company; Dr. Ryan D. Evans, Director of R\&D, for the financial support and Dr. Kuldeep Kishore Mistry, Product Development Specialist for the project support. Prof. Ali Dhinojwala and Prof. Stephen Chang of the College of Polymer Science and Polymer Engineering at the University of Akron have provided valuable insight into the properties and behavior of polymers. We also acknowledge BASF for providing polymer samples for this research. We are especially grateful to Dr. Scott Bair at Georgia Institute of Technology for the design, construction, and guidance in the high-pressure viscometer tests.

Tribol Int. 39, 1474-1481. doi: 10.1016/j.triboint.2005. 10.013

Dowson, D., and Hamrock, B. (1976). Numerical evaluation of the surface deformation of elastic solids subjected to a Hertzian contact stress. ASLE Transac. 19, 279-286. doi: 10.1080/05698197608982804

Dyson, A., and Wilson, A. (1965). "Paper 3: film thicknesses in elastohydrodynamic lubrication by silicone fluids," in Proceedings of the Institution of Mechanical Engineers, Conference Proceedings (Leeds), 97-112. doi: 10.1243/PIME_CONF_1965_180_323_02

Grubin, A., and Vinogradova, I. (1949). Fundamentals of the hydrodynamic theory of lubrication of heavily loaded cylindrical surfaces. Invest Contact Mach Components 30,115-166.

Hamrock, B. J., and Dowson, D. (1976). Isothermal elastohydrodynamic lubrication of point contacts: part 1-Theoretical formulation. J. Tribol. 98, 223-228.

Hamrock, B. J., and Dowson, D. (1978). Elastohydrodynamic lubrication of elliptical contacts for materials of low elastic modulus I-fully flooded conjunction. J Tribol. 100,236-245.

Hamrock, B. J., Schmid, S. R., and Jacobson, B. O. (2004). Fundamentals of Fluid Film Lubrication, 2nd Edn. New York, NY: CRC press, McGraw-Hill.

Harrison, G. (1976). The Dynamic Properties of Supercooled Liquids. London; New York, NY: Academic Press.

Khonsari, M. M., and Booser, E. R. (2008). Applied Tribology: Bearing Design and Lubrication, 2nd Edn. Hoboken, NJ: John Wiley \& Sons.

LotfizadehDehkordi, B., Shiller, P. J., Mistry, K. K., and Doll, G. L. (2016). "High Pressure Viscosity and Tribology of Lubricants with Viscosity Modifiers Additives" in Proceedings of 2016 STLE Annual Meeting, (Las Vegas, NV).

Mary, C., Philippon, D., Lafarge, L., Laurent, D., Rondelez, F., Bair, S., et al. (2013). New insight into the relationship between molecular effects and the rheological behavior of polymer-thickened lubricants under high pressure. Tribol Lett. 52, 357-369. doi: 10.1007/s11249-0130214-y

Vergne, P., and Bair, S. (2014). Classical EHL versus quantitative EHL: a perspective part $\mathrm{i}$-real viscosity-pressure dependence and the viscositypressure coefficient for predicting film thickness. Tribol Lett. 54, 1-12. doi: $10.1007 / \mathrm{s} 11249-014-0302-7$

Conflict of Interest Statement: BL was a student at the University of Akron during this research. He is now employed by the ExxonMobil Corp and declares no competing interests. The authors declare that this study received funding from the Timken Company. The funder provided access to tribological test apparatus for wear measurements performed on selective solutions. All authors declare no conflict of interest.

Copyright (C) 2019 LotfizadehDehkordi, Shiller and Doll. This is an open-access article distributed under the terms of the Creative Commons Attribution License (CC BY). The use, distribution or reproduction in other forums is permitted, provided the original author(s) and the copyright owner(s) are credited and that the original publication in this journal is cited, in accordance with accepted academic practice. No use, distribution or reproduction is permitted which does not comply with these terms. 